Василенко Л.А. Социальные инновации: освоение будущего или воспроизводство социального прошлого? // ВЕСТНИК МНЭПУ 2011. № 1. С. 19-30. Vasilenko L.A Social innovation: mastering the future or reproducing the social past? // Bulletin of MNEPU 2011. № 1. C. 19-30. https://elibrary.ru/item.asp?id=23917364

\title{
Василенко Л.А.
}

доктор социологических наук, профессор Российской академии народного хозяйства и государственной службы при Президенте РФ, почетный работник высшего профессионального образования

\section{СОЦИАЛЬНЫЕ ИННОВАЦИИ: ОСВОЕНИЕ БУДУЩЕГО ИЛИ ВОСПРОИЗВОДСТВО СОЦИАЛЬНОГО ПРОШЛОГО?}

Социальная инновация представляется как образ будущего, а мода на ее распространение - как социальная эпидемия. В статье рассматривается проблема возникновения, распространения и самозапуска моды на социальные инновации. Классификация моделей распространения социальных инноваций основана на оценке состояния целостности социальной системы, последствий качественных ее изменений. С этой точки зрения модели разделены на три группы: автопоэзисные, синергийно-интегрирующие и открывающие.

Ключевые слова: социальная инновация, образ будущего, возникновение инноваций, распространение инновации, социальные эпидемии, самозапуск моды на социальную инновацию, инфраструктура инноваторов, мерчандайзинг социальных инноваций, дизайн социальных отношений, социальная ценность инновационного продукта, модели трансфера социальных инноваций, классификация моделей трансфера социальных инноваций; опережающая адаптация, сопротивление социальным изменениям, социальное конструирование поведения инноваторов, эпицентры социальной активности, общественный аудит конкурентной способности инновации, социальные инвестиции.

\section{Vasilenko L.A. Social innovation: development of the future or reproduction of the social past?}

Social innovation is the image of the future, and fashion for its distribution becomes a social epidemic. The article deals with the problem of emergence, distribution and self-triggering introduction of social innovation into fashion. The classifi cation of distribution models of social innovations is based on the assessment of the integrity of the social system and consequences of its qualitative changes. From this perspective, the model is divided into three groups: autopoesis, synergetically integrating and opening up.

Keywords: social innovation, the image of the future, the emergence of innovation, distribution innovation, social epidemics, self-triggering introduction social innovation, infrastructure, innovators, social merchandising innovation, design, social relations, the social value of innovative product, the model of transfer of social innovation, classifi cation of transfer of models of social innovation; anticipatory adaptation, the resistance of social change, social construction of the behavior of innovators, social activity, a public audit of the competitive ability of innovation, social investment. 
Тема управления будущим становится все более модной. С одной стороны, это проявление нарастающей потребности российского социума осознавать, куда идет Россия, к чему стремится. С другой стороны, это ощущение неудовлетворенности качеством происходящих перемен. Становится все более очевидным, что модернизационные процессы идут неоптимально.

В Национальном докладе Ассоциации менеджеров инновация представляется как результат инновационной деятельности (инновационный продукт, услуга, технология и/или новая организационная форма), обладающий явным качественным преимуществом и обеспечивающий экономическую и/или общественную выгоду [10, 15]. Речь здесь ведется исключительно об изменениях средств и методов организации и технологии производства, или об обеспечении функционирования предприятий, хотя авторы подчеркивают получение качественных преимуществ результата инновационной деятельности, имеющих как экономическую, так и общественную составляющую. На деле общественная составляющая даже если и получает реальные выражения на уровне отдельного предприятия, то в статистических показателях на других управленческих уровнях уже совершенно не учитывается и не отслеживается, т.е. не является важной для руководителей отрасли, региона, страны.

Результат проходящей модернизации не устраивает пока ни отдельные предприятия, ни граждан, ни руководство страны. Заимствование вырванных из контекста западного развития отдельных модернизационных технологических и производственных инноваций, продвигаемых в России, не дает результата. Это определяется несоответствием социальной и управленческой среды, отсутствием необходимых социальных условий и рыночных механизмов, в которых модернизационные процессы осуществляются. Руководители, воспитанные в культуре «управляемых винтиков», стремятся к воспроизводству привычных и понятных им отношений, к полному контролю над процессами, ресурсами, финансами, технологиями. Это требует наличия многочисленных контролирующих, надзирающих и посреднических структур, разрастающегося аппарата. И все это во имя создаваемого будущего.

Представленный процесс можно назвать скорее воссозданием «пережитков будущего» или воспроизводством «социального прошлого», что происходит в случае воплощения очередного желаемого модернизационного плана в условиях отсталой социальной среды и социализации феодального типа. Данное социальное воплощение вряд ли отвечает духу времени, оно требует социальности новой, для которой характерна демократичность, открытость к развитию, умение действовать; согласованности действий с распределением полномочий и ответственности.

Bсе это должно базироваться на главных цивилизованных столпах нравственности, духовности - жизненно важных качеств, поскольку будущее не прощает безнравственности и бездуховности. Тема новой нравственности особенно ярко звучала у Н. Моисеева. В период трансформации социальных отношений общество должно быть готово корректировать основные 
принципы в свете приобретенного нового опыта. Ценности не могут быть абсолютными и совершенными, требуется периодическое критическое их переосмысление $[12,85]$. Если не развивать социальность, соответствующую современности, то никакие модернизационные процессы не станут общей практикой. Результатом будут эксклюзивные очень затратные «осколки» желаемого будущего. Целостного инновационного без социального создать невозможно. В широком смысле социальную инновацию можно определить как образ строящегося будущего. Для модернизации на основе новой социальности необходимы политическая воля, создание соответствующих условий, мода на нравственность, честный образ жизни, служение Родине, а также наличие свободы воли участников, сочетание управленческих механизмов с механизмами самоорганизации. Первый и второй компоненты являет нам Председатель Правительства РФ В.В. Путин, который лично инициирует и продвигает конкретные глобальные проекты века, объединяя в них партнеров разных стран, форм собственности, отраслей. Здесь есть последователи, имеются тенденции к широкому участию граждан. Третий компонент - нравственность и честный образ жизни, к сожалению, пока не в чести, не поощряется органами власти и часто рассматривается общественностью как анахронизм. Подчеркнем, что именно отсутствие социокультурной составляющей уменьшает результативность инновационных процессов, тормозит модернизацию, развитие страны.

Если инновация созрела, а ее место в будущем пока неясно, можем ли мы действовать быстро, решительно и бескомпромиссно? Вопрос непростой, ведь главное кредо профессионала-управленца - «не навреди». В наше динамичное время справедлива еще одна мудрость - кто не успел, тот опоздал.

Четвертый компонент - сочетание управленческих механизмов с механизмами самоорганизации - связан с феноменом распространения инновации, вызывающей качественные изменения в системе. Эти изменения, во-первых, связаны с общественными отношениями, культурой, как субъекта, так и объекта управления, «воспроизводство условий для инноваций есть проблема культуры» (по М. Кастельсу). Во-вторых, они направлены на решение социально значимых проблем, оказывая существенное влияние на общество и на систему социального управления. Втретьих, проникновение социальных инноваций в систему управления зависит от личностных качеств руководителей, уровня их культуры и гражданской инициативы, а также от степени интеграции и взаимовлияния их социальных действий. Такой процесс может быть управляемым или носить самоорганизационный характер как итог выбора системой одной из тенденций ее развития. Сознательно продвигая инновации, социальный инженер, конструктор, независимо от масштаба задуманного, создает образ желаемого будущего. Сопоставляя достигнутое со своим замыслом, он при необходимости вносит коррективы либо в процесс построения, либо в свой замысел будущего, включая механизм положительных или отрицательных 
обратных связей. При этом последствия для социальной системы могут быть различными:

- изменения одного или нескольких существующих параметров поряд-ка во всей социальной системе или ее подсистеме;

- рождения нового параметра порядка, новых социальных связей или способов их формирования, проявления нового качества социальной системы;

- рождения принципиально новой подсистемы в рамках модернизирующейся старой социальной системы;

- рождения принципиально новой социальной системы, сопровождае-мой разрушением основ старой социальной системы, ее катастрофы.

Для реализации социальной инновации должно быть наличие: новой идеи, образа социального изменения; хотя бы одной проактивной социальной группы, имеющей интерес к данному нововведению; социального капитала, социальных и экономических ресурсов в распоряжении социально активной группы, заинтересованной в инновации; развитых социальных коммуникаций, способствующих распространению социальной инновации.

Организация совместных действий по внедрению инноваций представляет собой особую разновидность социального управления. Трудность связана с необходимостью отслеживать стратегическую направленность развития социума. Кроме того, жизненно важно учитывать степень гармонизации взаимовлияния участников инновационного процесса и изменяющейся социальной среды и социального пространства (взаимоотношений, интересов и активностей различных социальных групп). Применение технологий инновационного маркетинга для организации самоорганизующейся среды, способствует востребованности и реализации инноваций. В этом контексте нет смысла разделять инновации на социальные (т.е. формирующие современные социальные отношения), технические, технологические (т.е. стимулирующие производство инновационной продукции и ее сбыт). Они, как правило, распространяются вместе, ибо технологические новации требуют изменения устройства социальной структуры в организации, а всякое социальное обновление обязательно влечет за собой нарастающую потребность в модернизации производства, техники и технологий.

Поток создаваемых инновационных технологий требует оформленности специфической информационной неравновесной среды, социальных и финансовых инвестиций, создания специальной инфраструктуры инноваторов. С одной стороны, таких людей в России много - в продуцировании идей и инноваций в социальной жизни мы основательно поднаторели, действия инноваторов направлены зачастую против существующих правил, в обход закона. Отметим, что если общество и приняло новые образцы социальной и технико-технологи ческой практики и оценило их как позитивные, мы не умеем их быстро распространять, а также своевременно закреплять необходимые правовые нормы.

Социологические опросы показывают, что российские предприниматели уверены - создать ничего нового и перспективного нельзя, если строго 
соблюдать законы. Конечно, это закономерно, ведь нормативно могут регулироваться только проверенные социальной практикой отношения, а возникающие способы достижения новых потребностей требуют осторожного подхода. В «проверках на прочность» мы медлительны, рискуем никогда не легитимизировать новшества. Но главные проблемы российского социума зависть и стремление к уничтожению всех потенциальных конкурентов. А если инновацию нельзя применить, возникает эффект, известный нам по фильму «Гений».

Поэтому установление новой социальной организации в России всегда требует политической воли и усилий первых лиц государства, а также наличие команды специалистов, обученных применению технологий продвижения инноваций и отслеживанию их последствий инновационных процессов. Они должны понимать их суть и по возможности направлять усилия в русле одной из имеющихся тенденций развития социальной системы, с учетом как внутренних факторов ее развития, так и факторов влияния внешней среды.

Одна из ключевых составляющих управления социально-инновационными процессами - определение возможного изменения поведения сложной самоорганизующейся системы как в результате целенаправленного управленческого воздействия, так и под влиянием диффузии инноваций. Наиболее эффективными являются управленческие воздействия, подталкивающие естественно возникающие самоорганизационные процессы. Так, распространение инноваций от индивида к индивиду в значительной степени подобно механизму распространения эпидемий - сверхбыстрого массового распространения «возбудителя инфекции» (в нашем случае всеобщего увлечения инновациями).

Американский ученый М. Гладуэлл так выражает этот аспект: «Лучший способ понять то, как возникают направления моды; как происходят приливы и отливы волны преступности; или, в этом же ключе, как неизвестные книги превращаются в бестселлеры; как распространяется среди подростков пристрастие к курению; как возникнет феномен молвы или же любые другие необъяснимые явления, характерные для сегодняшней повседневной жизни, - это относиться к ним как к эпидемиям» [3, 2]. Он сформулировал три слагаемых эпидемии, которые обеспечивают возможность логического понимания социальных эпидемий: закон малого числа, фактор прилипчивости и сила обстоятельств.

Сила обстоятельств определяет контекст социальной среды и восприимчивость людей к ее влиянию, специфические и относительно малые элементы окружения могут стать переломными моментами, кардинально меняющими ситуацию. Гладуэлл подчеркивает, что такие моменты в контексте среды - это то, что мы можем изменить. Особенности нашего ближайшего социального и материального мира (город, в котором мы живем, люди, с которыми мы сталкиваемся) играют огромную роль в формировании того, кто мы есть и как мы действуем. Глаудэлл указывает на возможность достижения результатов за счет совокупного воздействия на факторы риска среды, приводя пример распространения и «свертывания» эпидемии преступности: 
«Мы можем застеклить разбитые окна и стереть граффити, в первую очередь, удалив сигналы, которые поощряют преступность».

Любая инновация есть некое начало, от которого часто зависит, состоится она или будет отторгнута социумом. Ее реализация не возможна без креативной самоорганизующейся среды возникающих инноваций, а значит, в такой среде должны действовать механизмы социального рынка. Н Моисеев использует в таких случаях слово «Рынок» с большой буквы, подчеркивая отличие смысла от термина «базар».

Становлению социального рынка посвящено исследование О. Романовой. В основе возникновения нового компонента социального рынка лежат механизмы социорыночной конкуренции, кооперации и социального отбора. Результат - возникновение социальных сборок* или самотрансформаций фундамента любого социального образования. Социальный рынок порождает наряду с традиционными продуктами (товарами и услугами) такие продукты как социальные сборки, деньги, привилегии, социорыночные отношения и связи, социальное рыночное сознание, способы жизнедеятельности. Сегодня есть инновационный рынок (рынок социальных программ, «рынок директоров», рынок моделей государственной службы и т.п.), выделились новые сегменты или сферы деятельности (рынок инноваций, культуры, недвижимости, ценных бумаг, финансовый рынок). Своя специфика в новых продуктах социального обмена - (знания, социальные нормы, программы, отношения, смыслы, символы); в обращении капиталов (социальный, культурный, символический, экономический) [11]. Одна из технологий рынка инноваций - мерчандайзинг социальных инноваций, представляющий собой организацию среды как специфического рыночного пространства социальных инноваций. Через информационную коммуникативную среду «возбудитель инфекции» может быстро распространяться, увеличивая скорость «заражения». При этом индивиды могут территориально находиться очень далеко. Такие «возбудители инфекции» инициируют нарастающий процесс изменения привычного поведения индивидов и их сообществ через новые смыслы. Их введение создает «новые ансамбли параметров состояния в пространстве феноменов» [5, 99], порождает неравновесность. Некоторые из них находят свое положение в существующей системе параметров порядка, что для изменяющейся социальной системы становится началом необратимых процессов. В результате создаются условия для появления моды на инновацию, значимо меняющую поведение граждан. Мерчандайзинг основан на таком информационном пространстве, в котором покупатель сам, без помощи продавца, может ориентироваться в динамически меняющейся информационной среде возникающих инноваций. В такой среде интерактивно отражаются действия каждого участника - создателя новой идеи, производителя и покупателя инновации. 
* Социальные сборки - спонтанные или организованные социальные образования, которые выступают в роли продуктов рынка (идея, нормативно-правовой акт, проект, программа). Прим. aвm.

Закон малого числа описывает особенности распространения новой моды. Глаудэлл сформулировал его следующим образом: есть уникальные люди, которые способны начать эпидемию. Мерчандайзинг можно рассматривать как дизайн социальных инноваций, искусство созидания покупателей и продавцов такого специфического товара как инновации. Эти субъекты каждым своим действием формируют новый дизайн социальных отношений, воссоздают специфическую среду, в которой возникает спрос на инновацию. Здесь выгодно ее производить, продвигать, покупать. Они формируют своеобразный прототип института посредников, ориентирующихся в спросе и владеющих навыками «продавцадистрибьютора», способного разрекламировать такой специфический товар как инновация и продвинуть его на рынке инноваций.

В итоге как в рынке культуры могут возникать новые институты - институт копирайта и копилефта, институт брендинга, устанавливающие договоренность о разделе полномочий между автором инновации, посредником и потребителями. Как причиной эпидемии гриппа может быть всего один больной человек, так и волну распространения нового образа будущего (инновации) могут спровоцировать всего несколько человек [3, 2-7]. Успех социальных эпидемий тоже обеспечивает небольшое количество активных людей, первыми подхватившими ее «вирус». Запуск моды на эпидемию осуществляется экстраординарными усилиями нескольких "переносчиков вируса эпидемии». И множество индивидов становятся «зараженными». «Все, что нужно для распространения социальной эпидемии - это найти таких людей», которые выступают для широкого круга людей в качестве «объединителей», «знатоков» и «торговцев», обладающих особыми способностями к общению (М. Гладуэлл).

Итак, применение мерчандайзинга социальных инноваций для самозапуска «моды» на продвигаемую инновацию включает когерентные действия небольшой группы людей, в которой распределены социальные роли на основе подхода Гладуэлла. «Знатоки» - это инженеры по знаниям, формирующие базы знаний об инновациях в соответствующей области науки и практики. Их задача - умело фиксировать каждую идею, каждое организационное, технологическое, техническое достижение, выкладывая образцы возникающих в социальной или коммерческой практике инноваций, оформляют на каждую из них соответствующий документ, аналог патента на изобретение, включающий описание полезных свойств и технологий. Поскольку в пространстве социального рынка происходит обмен не только услугами, но и знаниями, идеями, социальными нормами, программами, отношениями и смыслами, в дополнение к цене, воплощенной в деньгах, "знатоки» формулируют смысловое выражение социальной ценности инновационного продукта. «Объединители», по Гладуэллу, обладают подсознательным и врожденным навыком к созданию социальных связей. В 
нашем случае «объединители» - это коммуникаторы, находящие возможных потребителей, производителей, конкурентов, определяющие их позитивные и негативные качества, потенциальные возможности, демонстрируя динамику роста способности зарождающейся инновации к конкурентному противостоянию, т.е. занимаются своеобразным лоббированием, «продвижением», «выращиванием» возникшего слабого ростка нового. Такой организатор должен обладать административными полномочиями, поскольку сила объединителей в их чрезвычайном влиянии на организационную систему.

Фактор прилипчивости или заразность проявляется в способах подачи сообщения-вируса приводить к массовому заражению и ускоренному развитию социальной эпидемии. Есть специальные способы сделать обращение запоминающимся, относительно простые приемы внесения поправок в то, как подается или как выстраивается информация в кадрах киноленты. Эти поправки могут сыграть решающую роль. Данную работу могут выполнять харизматичные люди, называемые М. Гладуэллом «торговцы», а в современных представлениях специалисты особого PRa. Ими могут быть применены маркетинговые технологии - сэмплинга (оформление образца инновации), рефрейминга (заключение появившегося образца в новое обрамление), брендинга (формирование ассоциаций с определенными свойствами и характеристиками продвигаемой инновации у будущих потребителей). Это влияние на сознание будущих творцов нового, производителей и потребителей инноваций. Символичным изменением смысла в наше время может стать фраза: «кадры решают все», имея в виду кадры специализированного PRa.

Рассматривая управление как синхронизацию действий управленческих кадров, подчеркнем, что цель такого управления - достижение когерентных усилий всех участников - «знатоков», "объединителей» и «торговцев», которые могут привести к массовому спросу на появление инноваций. Их, т.е. инновации, станет выгодно создавать, выставлять на аукцион и конкурс заявок на получение гранта, организовывать торги на бирже инноваций и продавать.

В настоящее время в результате активной деятельности руководства страны появляется возможность интегрировать усилия многих участников на территории Сколкова - современного аналога Силиконовой долины. Если мы остановимся только на повторении сути инновационной экономики, явленной нам созданием Силиконовой долины - платформы компьютерной индустрии США, то мы в очередной раз не сможем «догнать и перегнать Америку». Общая схема там сводится к универсальной модели эволюционного развития: наследование - мутация - конкуренция - отбор - усиление наследование. Это образует замкнутый цикл, который, по сути, является замкнутой кольцевой структурой. Данный цикл не включает развитие самоподдерживающихся и саморазвивающихся социо-инновационных процессов.

В решении новых задач можно использовать также и опыт построения советских наукоградов, директивно созданных в 30-х, 50-х и 70-х гг. для 
решения важнейших проблем оборонной направленности. Данный опыт надо освобождать от устаревших социальных отношений, формируя современные взаимодействия в условиях новой сетевой среды, что позволит освободить Долину инноваций “Сколково» от монополизма, который проглядывает уже сегодня.

Суть избранной стратегии построения иннограда «Сколково» заключается в выработке механизма государственных интервенций для стимулирования инновационного развития в отдельных секторах экономики или на отдельных территориях. Но эта стратегия не дополняется современной сетевой системой межрегионального и межстранового взаимодействия в условиях среды инновационной активности, не привязанной жестко к территориям. Например, появилась технология создания технологий (метатехнология), технополисы, межстрановые кластеры в Ирландии, Германии, Израиле, Японии. «Необходимы не жесткие границы, а инструменты отбора, методология предварительного проигрывания различных сценариев. Фабрики новаций, венчурные команды» [9].

Таким образом, используя механизмы технологий саморазвития инновационных предпринимателей многих территорий России, следует сосредоточить усилия на базовых центрах социально-инновационной активности в конкурентной среде, создавать «притяжение» к ним в динамической коммуникативной среде. Но для этого желательно скомплектовать команды для сопровождения внедрения победивших в отборе инноваций - «объединителей», «знатоков», «торговцев».

Возможность выбрать эффективную форму инновационной деятельности позволит наличие большого разнообразия моделей трансфера инноваций [1, 78-84]. Методологической основой представленных в настоящей работе моделей выступает социосинергетика. Основным классификационным признаком группировки таких моделей выбрана оценка системного эффекта от совокупных взаимодействий всех акторов социальных действий, участвующих в продвижении социальной инновации (или препятствующих этому продвижению). Согласно подходу новосибирского ученого А. Крейка, предложенному в работе «Управление системными эффектами инновационная модель управления» [7, 261], оценка основана на качественном состоянии изменяющейся целостности социальной системы. $C$ этой точки зрения модели разделены на три группы: автопоэзисные, синергийно-интегрирующие и открывающие модели управления изменениями.

Автопоэзисные модели управления изменениями предполагают локальные изменения существующих параметров порядка в социальной системе. Речь идет об эффекте адаптивности-дезадаптивности, формируемом целенаправленно или возникающем в результате самоорганизации. Название группы исходит из сущности термина «автопоэзис» (autopiesis). Автопоэзис означает способ существования (воспроизведения, самоорганизации) социальной системы, поведение системы, которое позволяет ей самовоспроизводиться и существовать автономно в условиях изменяющейся 
среды. Другими словами - это способ воспроизведения системой самой себя в активном взаимодействии с внешней средой, "достраивании социальных миров», гармонизации социального пространства, пересмотра правовых норм, инициативного реагирования на возникающие социальные флуктуации, а также преодоления дестабилизирующего взаимовлияния участников инновационного процесса. В данной группе представлено пять моделей:

«Опережающая адаптация к продвижению инноваций в социальную практику», учитывающая естественное стремление социальной системы к устойчивости, возможность отторжения системой инновации из-за опасения деструктивных изменений;

"Корпоративная социальная ответственность в контексте прав человека» - рассматривает активное взаимодействие изменяющейся социальной системы и инноваторов по формированию новых правил жизнедеятельности человека в условиях изменяющейся внутренней и внешней среды. В процессе применения модели речь идет о своеобразном достраивании социальных миров, гармонизации изменяющегося социального пространства;

"Снижение сопротивления социальным изменениям» - направлена на преодоление дестабилизирующего взаимовлияния непосредственных участников инновационного процесса, а также их влияния на социальные отношения изменяющейся среды, в которой действуют участники процесса;

"Согласование социальных норм» - использует компенсирующие механизмы социальной адаптации, направленные на опережающую нейтрализацию негативных тенденций развития системы, дезорганизации, формирования деструктивных социальных связей через включение граждан в процесс принятия новых правовых норм в соответствии с позитивным для них вектором развития социальной системы. В модели задействованы компенсирующие механизмы гражданского контроля одного из самых простых и демократичных способов воздействия на органы власти и другие организационные структуры, обеспечивающие жизнедеятельность граждан;

«Социальная инициатива в целях конструктивного развития» направлена на преодоление возникших флуктуаций, вызывающих социальные конфликты. Речь идет о запуске процессов перенаправления энергетических потоков на конструктивную самоорганизацию, на решение проблем, вызывающих социальную несправедливость, через реализацию социальной инициативы.

Группа синергийно-интегрирующих моделей предопределяют рождение новых социальных связей и согласование ритмов жизнедеятельности, в результате которых качественное состояние социальной системы значительно изменяется, проявляются новые грани синергийного эффекта. Речь идет о возникновении эффекта связности и когерентности в результате кооперации и/или интеграции* взаимодействующих акторов социального действия или нейтрализации эффекта «деструктивно- 
* Кооперация - важнейший социорыночный процесс, внутренний регулирующий механизм социального рынка. Термин «интеграция» в переводе с латинского означает восстановление, восполнение и происходит от слова «целый» (integer). Прим. авт.

сти», т.е. разрушения социальных связей или рассогласования ритмов жизнедеятельности элементов системы. Интеграционные процессы всегда сложны в силу того, что «не какие угодно структуры и не как угодно, не при любой степени связи и не на каких угодно стадиях развития могут быть объединены в сложную структуру. Существует ограниченный набор способов объединения, способов построения сложного эволюционного целого» $[6,8]$. Основная направленность моделей рассматриваемой группы - создание (или сборка) новой подсистемы или ее части через соединение различных компонентов (элементов). Методологической основой данной группы моделей является обоснование достижения эффекта синергии. Методы достижения определяются способом формирования связей, качества взаимодействий, условий и принципов объединения социальных общностей в общую сложную систему, которая являет качественно новое состояние. В данной группе представлено пять моделей: «Коэволюционное развитие», "Кластерная кооперация», «Межрегиональная интеграция», «Структурная интеграция», «Проектирование инновационных форм передачи полномочий от органов власти к негосударственным организациям».

Открывающие модели определяют процессы открытия социальных систем для будущего, зарождения принципиально новых параметров порядка, нового фрагмента социальной системы, а также коренной модернизации или разрушения параметров порядка старой социальной системы, мешающих ее развитию. Термин «открытость» выражает синергию материального и идеального начал природы [4, 24]. Общество, как и природные системы, предстает перед нами как производное открытого самоорганизующегося Мира. Открытость характеризуется не столько свободой обращения информации. Более важной является исходная самодостаточность, т.е. наличие на исходном уровне источника активности и самоорганизации, способность общества к постоянному движению, развитию. Будущее по Е.Н. Князевой, С.П. Курдюмову, конструктивно, активно и открыто, поскольку оно ведет отбор тех элементов настоящего, которые конгруэнтны, подобны возникающему будущему, но какая из спектра возможных структур возникает сейчас, определяется случайностью.

Степень открытости общества связана с развитием человека и его активностью, что выражается готовностью общества постоянно пересматривать систему ценностей и правил, по которым оно живет $[2,26]$. С точки зрения реализации потребности в целостности в социальных системах важным является учет динамической открытости изменяющихся социальных систем. Открытость в этом отношении актуализируется как предел и процесс изменения предела [8, с. 186], или, в терминологии социальной топологии, как граница и изменение границы топоса. Актуализация проблемы границ и 
процесса их изменения - ключевой момент анализа трансформации социального пространства. С точки зрения целостности системы можно говорить о возможности влияния на возникновение эффекта синергии за счет «возникновения или целенаправленного формирования новых правил и алгоритмов взаимодействий элементов социальной целостности в режиме кооперации.

В данной группе представлено пять моделей: Управление будущим через изменение культуры, Социальное конструирование поведения инноваторов, Эпицентры социальной активности, Общественный аудит конкурентной способности инновации, Социальные инвестиции.

\section{Библиография}

1. Василенко Л.А. Менеджмент социальных инноваций. - М.: Проспект, 2010.

2. Василенко Л.А. Интернет в информатизации государственного управления. - М.: Наука, 2008.

3. Гладуэлл М. Переломный момент. - М.: 2004. Цит. по материалам сайта «Свой бизнес» www.mybiz.ru.

4. Егоров В.С. Социальный реализм. - М., 1999.

5. Капустин В.С. Введение в теорию социальной самоорганизации. - М.: РАГС, 2002.

6. Князева Е.Н., Курдюмов С.П. Синергетика и принципы коэволюции сложных систем // Синергетика и социальное управление. - М., 1998.

7. Крейк А.И. Управление системными эффектами - инновационная модель управления // Инноватика государственного управления: прорыв в будущее. Материалы научнопрактической конференции / Под общей ред. д.с.н, д.м.н., проф. В.Л. Романова. - М.: Проспект, 2006.

8. Моисеев В.И. Логика всеединства. - М.: ПЕР СЭ, 2002.

9. Москалев И.Е. Феномен автопоэзиса в процессах социальной самоорганизации // Синергетическая парадигма. - М.: Прогресс-Традиция, 2009.

10. Национальный доклад «Организационно-управленческие инновации: развитие экономики, основанной на знаниях» / Под ред. С.Е. Литовченко. - М., 2008.

11. Романова О.В. Становление института социального рынка. Авт. дисс. соц. наук. М.: РАГС, 2009.

12. Сорос Дж. Кризис мирового капитализма. Открытое общество в опасности / Пер. с англ. - М., 1999. 